\title{
Laser production of gas phase complexes of metal $\alpha$-aminophosphonic acid mixtures and their role in chiral recognition
}

\author{
A. Paladini, ${ }^{1}$ C. Calcagni, ${ }^{1}$ T. Di Palma,${ }^{2}$ M. Satta, ${ }^{1}$ M. Speranza, ${ }^{3}$ D. Scuderi, ${ }^{1,3}$ \\ A. Laganà, ${ }^{1}$ G. Fago, ${ }^{1}$ and A. Giardini Guidoni ${ }^{1,2}$ \\ ${ }^{1}$ Dipartimento di Chimica, Università di Roma “La Sapienza", pl. A. Moro 5, I-00185 Roma, Italy \\ ${ }^{2}$ CNR-Istituto Materiali Speciali, I-85050 Tito Scalo (Pz), Italy \\ ${ }^{3}$ Facoltà di Farmacia, Dipt. di Chimica e Tecnologia delle Sostanze Biologicamente Attive, \\ Università di Roma "La Sapienza", pl. A. Moro 5, I-00185 Roma, Italy
}

\begin{abstract}
Clusters between first-group metal ions and chiral $\alpha$-aminophosphonic acids have been readily generated by Pulsed Laser Ablation (PLA) and by Electrospray Ionization (ESI) and their fragmentation investigated by mass spectrometry. The complexes studied have the general formula $\left[\mathrm{Me}(\mathrm{I}) \mathrm{CL}_{2}\right]^{+}$, where $\mathrm{Me}(\mathrm{I})$ is $\mathrm{H}, \mathrm{Li}, \mathrm{Na}$, or $\mathrm{K}, \mathrm{C}$ is $(R)-(-)-\left(1\right.$-aminoethyl) phosphonic acid $\left(\mathbf{E}_{\mathbf{R}}\right)$ and $(S)-(+)-(1$-aminoethyl) phosphonic acid (ES $),(1 R)-(+)-\left(1\right.$-amino-2-methylpropyl) phosphonic acid $\left(\mathbf{P}_{\mathbf{R}}\right)$ and $(1 S)-(-)-(1$-amino-2-methylpropyl)

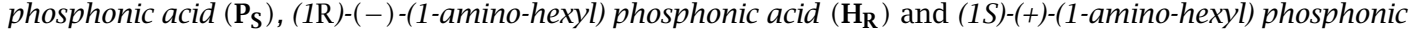
acid $\left(\mathbf{H}_{\mathbf{S}}\right)$, o-phospho-L-serine $\left(\mathbf{S}_{\mathbf{S}}\right)$ and $o$-phospho-D-serine $\left(\mathbf{S}_{\mathbf{R}}\right)$, and $\mathrm{L}$ is a reference $\alpha$-aminophosphonic acid (E, P, H or S) of defined configuration. Collision induced dissociation (CID) of diastereomeric $\left[\mathrm{Me}(\mathrm{I}) \mathrm{CL}_{2}\right]^{+}$ complexes leads to fragmentation patterns characterized by $[\mathrm{Me}(\mathrm{I}) \mathrm{CL}]^{+} /\left[\mathrm{Me}(\mathrm{I}) \mathrm{L}_{2}\right]^{+}$abundance ratios which depend upon the configuration of solute $C$. These different spectral features were correlated to the different stability of the diastereomeric $\left[\mathrm{Me}(\mathrm{I}) \mathrm{C}_{\mathrm{R}} \mathrm{L}\right]^{+}$and $\left[\mathrm{Me}(\mathrm{I}) \mathrm{C}_{\mathrm{S}} \mathrm{L}\right]^{+}$complexes in the gas phase.
\end{abstract}

\section{INTRODUCTION}

Interest in the analysis of biomolecules is rising everyday in molecular biology, biochemistry, pharmaceutical and chemical industries. Considering that the most of these molecules are chiral, the specificity of intermolecular interactions in these systems can lead to a pronounced enantioselectivity in a number of reactive processes. Various methodologies have been developed to discriminate between enantiomers in solid, liquid and gaseous phase. Recently attention has been paid to studies of the physicochemical properties of chiral systems in solvent free ambient by resonant laser spectroscopy [1, 2] and mass spectrometry under suitable conditions [3]. Both techniques rely on measuring the different stabilities of the diastereomers formed by interactions of enantiomers with a chiral reagent. However most of the molecules of biological interest are non-volatile and thermally labile compounds, which easily decompose upon heating. This problem has made difficult to study these molecules in the gas phase: many efforts have been made to find new vaporization methods. Among them, Pulsed Laser Ablation (PLA) has been demonstrated to be suitable for vaporizing chiral amino acids [4], but no evidence has been reported to date of PLA formation of their diastereomeric adducts.

An alternative methodology is ESI-CID-MS ${ }^{2}$ mass spectrometry which may provide information on the stability of chiral clusters simply through the measurement of the abundances of fragments peaks coming from the competitive dissociation of tetrameric cluster ion, according to the Cooks' kinetic method [5].

In this paper we report on the application of mass resolved PLA and ESI-CID-MS ${ }^{2}$ techniques to the enantiodiscrimination of several $\alpha$-aminophosphonic acids. $\alpha$-Aminophosphonic acids are the analogues of natural $\alpha$-aminocarboxylic acids in biological systems. They are used as pharmacological (antiviral and antibiotic) agents, enzyme inhibitors, herbicides and pesticides, catalysts in organic transformations, and finally they are the key building block of phosphono-peptides [6]. The biological activity of these compounds is related to their stereochemistry and is strictly dependent upon their affinity towards metal centers. For these reasons, we have investigated the affinity of $\alpha$-aminophosphonic acids towards first-group metals in the gas phase and how this is affected by solute configuration.

\section{EXPERIMENTAL}

The investigated molecules are $(R)-(-)-(1$-aminoethyl) phosphonic acid $\left(\mathbf{E}_{\mathbf{R}}\right)$ and $(S)-(+)-(1-a m i n o e t h y l)$ phosphonic acid (E $\left.\mathbf{E}_{\mathbf{S}}\right)$, (1R)-(+)-(1-amino-2-methylpropyl) phosphonic acid $\left(\mathbf{P}_{\mathbf{R}}\right)$ and (1S)-(-)-(1-amino-2methylpropyl) phosphonic acid $\left(\mathbf{P}_{\mathrm{S}}\right), \quad(1 R)-(-)-(1-$ amino-hexyl) phosphonic acid $\left(\mathbf{H}_{\mathbf{R}}\right)$ and $(1 S)-(+)-(1-$ amino-hexyl) phosphonic acid $\left(\mathrm{H}_{\mathrm{S}}\right)$, o-phospho-Lserine $\left(\mathrm{S}_{\mathrm{S}}\right)$ and o-phospho-D-serine $\left(\mathrm{S}_{\mathrm{R}}\right) . \mathrm{R}$ and $\mathrm{S}$ $\alpha$-aminophosphonic acids were all commercially 
available from Sigma Aldrich.

\subsection{Mass resolved pulsed laser ablation (PLA).} The experiments have been carried out using a commercial LAMMA 500 instrument from Leybold-Heraeus. A very intense pulse from a ND:YAG laser ( $\tau=6 \mathrm{~ns}$ ) is frequency quadrupled $(\lambda=266 \mathrm{~nm})$ and tightly focused on the sample. Solid samples of $\alpha$-aminophosphonic acids were dissolved in water/methanol solution and spread on an electron microscope metal grid. After solvent evaporation the grid was inserted into the sample stage and covered with a quartz window. The irradiation of the samples was performed in the vacuum chamber at a pressure of $10^{-8}$ torr and at a laser power in the range $10^{8}-10^{9} \mathrm{~W} / \mathrm{cm}^{-2}$. The resolved mass signals are detected by an electron multiplier, sent to a digital oscilloscope and stored on a PC. The data reported here concern positive ions, averaged over several spectra.

\subsection{Electrospray ionization mass spectrometry} (ESI-MS). The electrospray experiments were performed using a commercial API 100/300 triplequadrupole mass spectrometer from Perkin Elmer Sciex Instruments, equipped with an ESI source and a syringe pump. Operating conditions for the ESI source were as follows: spray voltage, $3.8 \mathrm{KV}$; capillary temperature, $298 \mathrm{~K}$; sheath gas $\left(\mathrm{N}_{2}\right)$ flow rate, 30 units (roughly $0.75 \mathrm{~L} / \mathrm{min}$ ). The experiments were conducted in the positive ion mode. Reported spectra represent the average of about 150 scans, each requiring 0.1 seconds. The sample was infused via a syringe pump at a flow rate of $10 \mu \mathrm{l} / \mathrm{min}$. In the full scan MS-MS-MS mode the parent cluster ion was first isolated and then subjected to a CID process, in an energy range of $2-18 \mathrm{eV}$ in the laboratory system.

The selected gas phase complexes were generated by electrospraying 50/50 water/methanol solutions containing a mixture of optically pure $\alpha$ aminophosphonic acids, $10 \mu \mathrm{M}$ each, and $2.5 \mu \mathrm{M}$ metal sulphate. Complexes between $\mathrm{H}^{+}$or $\mathrm{Na}^{+}$and the selected $\alpha$-aminophosphonic acids are observed in plain water/methanol solutions also in the absence of added salts.

\section{RESULTS AND DISCUSSION}

Mixtures of $\alpha$-aminophosphonic acids were studied by Laser Microprobe Mass Analysis (LAMMA). In the absence of a metal source, the solid $\alpha$-aminophosphonic acid mixtures produces mainly the ionized parent molecules and their fragments. Under these conditions, formation of ionised clusters is negligible. When a metal is added to the $\alpha$-aminophosphonic acid in the ablation region, signals up to quaternary complexes containing the metal appear in the mass spectrum. This indicates that the metal ion efficiently coordinates the $\alpha$-aminophosphonic acid and that the complexes formed are stable at the ablation temperature. Mixtures of two optically pure $\alpha$-aminophosphonic acids with first-group metals were studied. It is convenient to define the cluster ions as "homo" when the two $\alpha$ aminophosphonic acids have the same configuration and "hetero" in the opposite case. A typical LAMMA spectrum of $\mathbf{E}_{\mathbf{S}}$ and $\mathbf{H}_{\mathbf{S}}$ mixed with potassium is reported in Figure 1. Similar spectra have been monitored by replacing $\mathbf{H}_{\mathbf{S}}$ with $\mathbf{H}_{\mathbf{R}}$. The ion abundances of the hetero and homo clusters do not differ within the 4\% experimental errors, thus suggesting a very small difference in their stability.

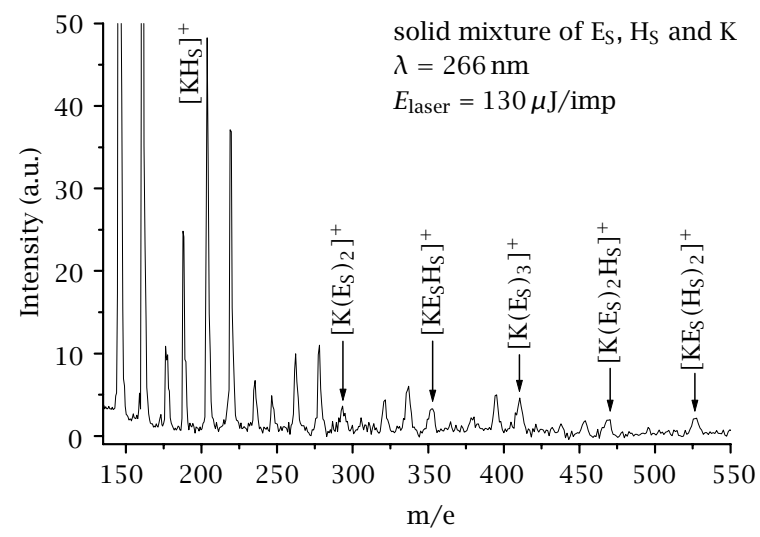

Figure 1. Laser ablation mass spectrum of a solid mixture containing $\mathbf{E}_{\mathbf{S}}, \mathbf{H}_{\mathbf{S}}$, and potassium. The spectrum was taken at $\lambda=266 \mathrm{~nm}$ and is the average of several spectra collected at $E_{\text {laser }}=130 \mu \mathrm{J} /$ pulse, in positive mode acquisition.

More insights into the relative stability of hetero and homo clusters is obtained by using the ESI-CID$\mathrm{MS}^{2}$ technique. The ESI-MS spectrum of $\mathbf{E}_{\mathbf{S}}$ and $\mathbf{P}_{\mathbf{R}}$ in plain water/methanol solutions is reported in Figure 2. The clusters $\left[\mathrm{H}\left(\mathbf{P}_{\mathbf{R}}\right) \mathrm{n}\right]^{+},\left[\mathrm{Na}\left(\mathbf{P}_{\mathbf{R}}\right) \mathrm{n}\right]^{+},\left[\mathrm{H}\left(\mathbf{E}_{\mathbf{S}}\right) \mathrm{n}\right]^{+}$, and $\left[\mathrm{Na}\left(\mathbf{E}_{\mathbf{S}}\right) \mathrm{n}\right]^{+}(n=1-4)$ are observed, together with all families of mixed clusters, including $\left[\mathrm{Na}\left(\mathbf{P}_{\mathbf{R}}\right)\left(\mathbf{E}_{\mathbf{S}}\right)_{2}\right]^{+}$ and $\left[\mathrm{H}\left(\mathbf{P}_{\mathbf{R}}\right)\left(\mathbf{E}_{\mathbf{S}}\right)_{2}\right]^{+}$. Analogous results are found for the other $\alpha$-aminophosphonic mixtures investigated. The CID experiments have been carried out on the ionic tetrameric clusters $\left[\mathrm{Me}(\mathrm{I}) \mathrm{CL}_{2}\right]^{+}$, where $\mathrm{Me}=\mathrm{H}, \mathrm{Li}, \mathrm{Na}$, or $\mathrm{K}, \mathrm{C}$ is the solute $\alpha$-aminophosphonic acid (the $\mathrm{S}$ and $\mathrm{R}$ enantiomers of $\mathbf{E}, \mathbf{P}, \mathbf{H}$ and $\mathbf{S}$ ), and $\mathrm{L}$ is a reference $\alpha$-aminophosphonic acid of defined configuration (the $\mathrm{S}$ or R enantiomer of $\mathbf{E}, \mathbf{P}, \mathbf{H}$ and $\mathbf{S})$. Their fragmentation leads essentially to the $[\mathrm{Me}(\mathrm{I}) \mathrm{CL}]^{+}$and $\left[\mathrm{Me}(\mathrm{I}) \mathrm{L}_{2}\right]^{+}$ species. This is illustrated in Figure 3(a),(b) reporting the CID fragmentation patterns of $\left[\mathrm{NaP}_{\mathbf{S}}\left(\mathbf{E}_{\mathbf{S}}\right)_{2}\right]^{+}$and $\left[\mathrm{NaP}_{\mathbf{R}}\left(\mathbf{E}_{\mathbf{S}}\right)_{2}\right]^{+}$, respectively.

According to the Cooks' quotient ratio method [5], the ion abundance $\mathrm{R}_{\mathrm{S}}=\left[\mathrm{Me}(\mathrm{I}) \mathrm{C}_{\mathrm{S}} \mathrm{L}\right]^{+} /\left[\mathrm{Me}(\mathrm{I}) \mathrm{L}_{2}\right]^{+}$and $\mathrm{R}_{\mathrm{R}}=\left[\mathrm{Me}(\mathrm{I}) \mathrm{C}_{\mathrm{R}} \mathrm{L}\right]^{+} /\left[\mathrm{Me}(\mathrm{I}) \mathrm{L}_{2}\right]^{+}$ratios of the fragments arising from energetic collision of $\left[\mathrm{Me}(\mathrm{I}) \mathrm{C}_{S} \mathrm{~L}_{2}\right]^{+}$and $\left[\mathrm{Me}(\mathrm{I}) \mathrm{C}_{\mathrm{R}} \mathrm{L}_{2}\right]^{+}$with a target gas under the same condi- 


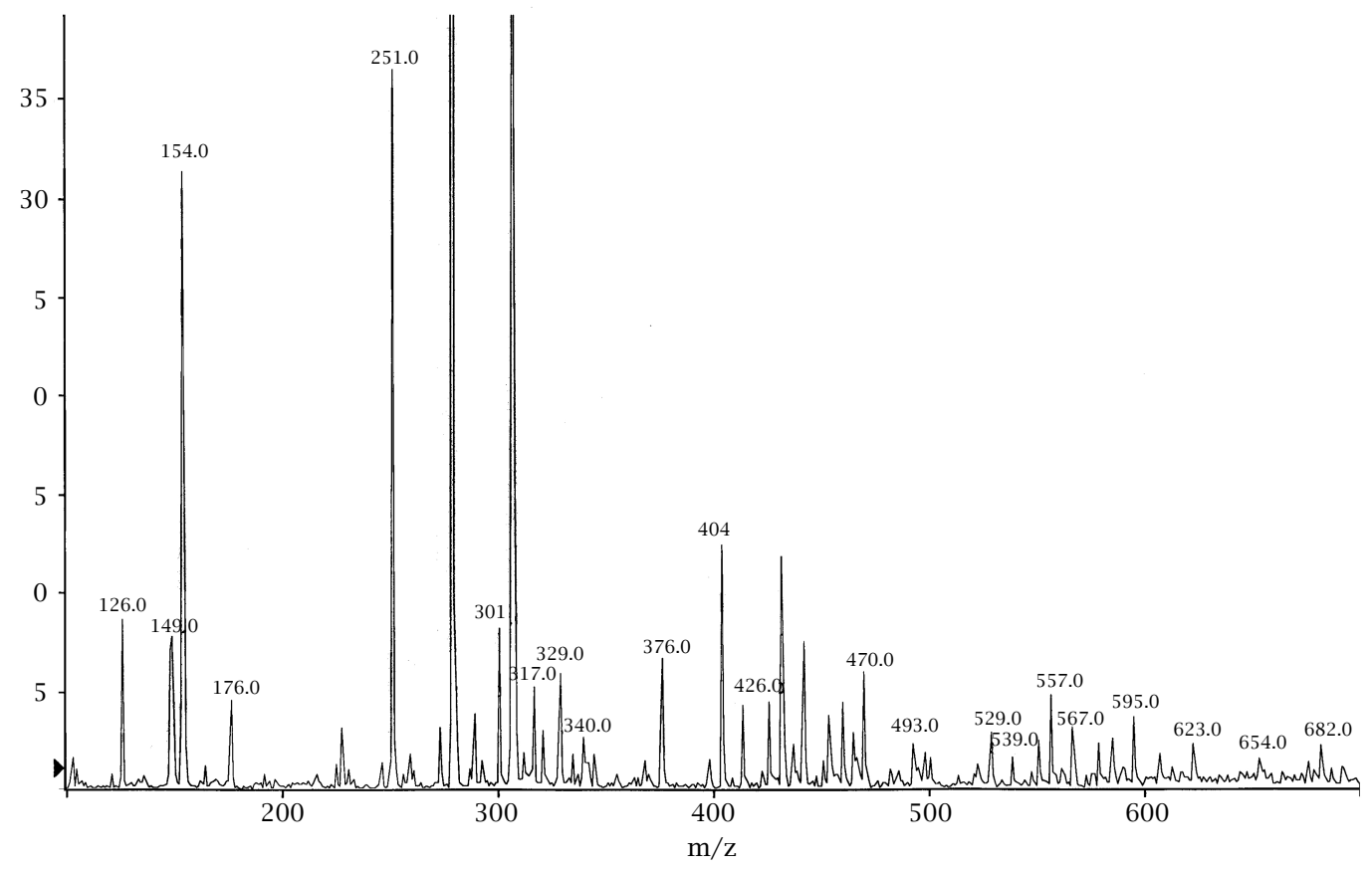

Figure 2. ESI-MS spectrum of a methanol/water $1: 1$ solution containing $\mathbf{E}_{\mathbf{S}}$ and $\mathbf{P}_{\mathbf{R}}, 10 \mu M$ each. The spectrum is the result of 150 scans.

tions provides a measure of the relative stability of the $\left[\mathrm{Me}(\mathrm{I}) \mathrm{C}_{\mathrm{S}} \mathrm{L}\right]^{+}$or $\left[\mathrm{Me}(\mathrm{I}) \mathrm{C}_{\mathrm{R}} \mathrm{L}\right]^{+}$complexes and, therefore, a tool for enantiodiscriminating the $\mathrm{C}$ solute. Dissociations occur as follows:

$$
\begin{gathered}
{\left[\mathrm{Me}(\mathrm{I}) \mathrm{C}_{\mathrm{S}}(\mathrm{L})_{2}\right]^{+} \stackrel{\left(k_{\mathrm{C}}\right)_{\mathrm{S}}}{\longrightarrow} \mathrm{k}_{\mathrm{L}_{\mathrm{L}}}\left[\mathrm{Me}(\mathrm{I}) \mathrm{C}_{\mathrm{S}}(\mathrm{L})\right]^{+}} \\
{\left[\mathrm{Me}(\mathrm{I}) \mathrm{C}_{\mathrm{R}}(\mathrm{L})_{2}\right]^{+} \stackrel{\left.(\mathrm{I})(\mathrm{L})_{2}\right]^{+}}{\stackrel{\left(k_{\mathrm{C}}\right)_{\mathrm{R}}}{\longrightarrow}} \underset{k_{\mathrm{L}}}{\left[\mathrm{Me}(\mathrm{I}) \mathrm{C}_{\mathrm{R}}(\mathrm{L})\right]^{+}}\left[\mathrm{Me}(\mathrm{I})(\mathrm{L})_{2}\right]^{+}}
\end{gathered}
$$

and $\left(k_{\mathrm{C}}\right)_{\mathrm{S}} / k_{\mathrm{L}}=\mathrm{R}_{\mathrm{S}},\left(k_{\mathrm{C}}\right)_{\mathrm{R}} / k_{\mathrm{L}}=\mathrm{R}_{\mathrm{R}}$.

The relative rates of the two competitive dissociations can be expressed as $R_{R} / R_{S}$ ratio, which is defined as the chiral resolution factor $\mathrm{R}_{\text {chiral }}$. When $\mathrm{L}$ has the $\mathrm{S}$ configuration, a value $\mathrm{R}_{\text {chiral }}>1$ indicates that the heterochiral $\left[\mathrm{Me}(\mathrm{I}) \mathrm{C}_{\mathrm{R}} \mathrm{L}\right]^{+}$complex is more stable than the homochiral $\left[\mathrm{Me}(\mathrm{I}) \mathrm{C}_{S} \mathrm{~L}\right]^{+}$one and vice versa. For $\mathrm{R}_{\text {chiral }}=1$ there are no stability differences and chiral discrimination is unattainable by this method.

Within the reasonable assumption that entropy effects on fragmentation are negligible, the difference between the bond dissociation energies of the trimeric clusters $\left[\mathrm{Me}(\mathrm{I}) \mathrm{C}_{S} \mathrm{~L}\right]^{+}$and $\left[\mathrm{Me}(\mathrm{I})(\mathrm{L})_{2}\right]^{+}$can be expressed as: $\ln \left[\left(k_{\mathrm{C}}\right)_{\mathrm{S}} / k_{\mathrm{L}}\right]=\ln \mathrm{R}_{\mathrm{S}}=\left(\Delta H_{0}\right)_{\mathrm{S}} / R T_{\text {eff }}$. A similar equation can be written for the other enantiomer $\mathrm{C}_{\mathrm{R}}: \ln \left[\left(\mathrm{k}_{\mathrm{C}}\right) \mathrm{R} / \mathrm{k}_{\mathrm{L}}\right]=\ln \mathrm{R}_{\mathrm{R}}=\left(\Delta H_{0}\right)_{\mathrm{R}} / R T_{\text {eff. }}$. Accord- ingly, the difference in the binding energies $\Delta\left(\Delta H_{0}\right)_{\mathrm{R}-\mathrm{S}}$ between the hetero $\left[\mathrm{Me}(\mathrm{I}) \mathrm{C}_{\mathrm{R}} \mathrm{L}\right]^{+}$and homo $\left[\mathrm{Me}(\mathrm{I}) \mathrm{C}_{\mathrm{S}} \mathrm{L}\right]^{+}$ clusters can be expressed in terms of $\mathrm{R}_{\text {chiral }}:\left(\Delta H_{0}\right)_{\mathrm{R}}-$ $\left(\Delta H_{0}\right)_{\mathrm{S}}=\Delta\left(\Delta H_{0}\right)_{\mathrm{R}-\mathrm{S}}=R T_{\text {eff }} \ln \mathrm{R}_{\text {chiral }}$, as shown in Figure 4 .

The chiral resolution factors $\mathrm{R}_{\text {chiral }}$ for a number of diastereomeric $\left[\mathrm{Me}(\mathrm{I}) \mathrm{C}_{S} \mathrm{~L}_{2}\right]^{+}$and $\left[\mathrm{Me}(\mathrm{I}) \mathrm{C}_{\mathrm{R}} \mathrm{L}_{2}\right]^{+}$ complexes has been measured. The reproducibility of the method was investigated by changing the chirality of the reference and the reference with the solute. Heat of formation of the clusters $\left[\mathrm{Me}(\mathrm{I}) \mathrm{C}_{S} \mathrm{~L}_{S}\right]^{+}$and $\left[\mathrm{Me}(\mathrm{I}) \mathrm{C}_{\mathrm{R}} \mathrm{L}_{\mathrm{R}}\right]^{+}$, one mirror image of the other, are the same. As a consequence the chiral factors for the clusters $\left[\mathrm{Me}(\mathrm{I}) \mathrm{CL}_{S}\right]^{+}$and $\left[\mathrm{Me}(\mathrm{I}) \mathrm{CL}_{\mathrm{R}}\right]^{+}$are one the reciprocal of the other (i.e., $\left.\mathrm{R}_{\text {chiral }}\left[\mathrm{NaH}\left(\mathbf{S}_{\mathbf{R}}\right)_{2}\right]^{+}=1 / \mathrm{R}_{\text {chiral }}\left[\mathrm{NaH}\left(\mathbf{S}_{\mathbf{S}}\right)_{2}\right]^{+}\right)$. Similarly it can be shown that exchanging the reference with the solute and viceversa the $\mathrm{R}_{\text {chiral }}$ value doesn't change (i.e., $\left.\mathrm{R}_{\text {chiral }} \mathrm{NaH}\left(\mathrm{S}_{\mathbf{R}}\right)_{2}\right]^{+}=\mathrm{R}_{\text {chiral }}\left[\mathrm{NaS}\left(\mathbf{H}_{\mathbf{R}}\right)_{2}\right]^{+}$) [7]. Taking into account these considerations average values of $\mathrm{R}_{\text {chiral }}$ can be determined for each cluster studied.

In Table 1 the average values of $\mathrm{R}_{\text {chiral }}$ are reported for some systems, together with the corresponding $\Delta\left(\Delta H_{0}\right)_{\mathrm{R}-\mathrm{S}}$ terms at an effective temperature $T_{\text {eff }}=$ $950 \mathrm{~K}$ [3]. It can be seen that the stability differences between metal ionized diastereomeric clusters can be estimated as ranging from about 0 to $3.2 \mathrm{KJ} / \mathrm{mol}$. These values are generally lower than those measured for neutral and ionized diastereomeric clusters of chiral alcohols in gaseous phase at temperatures of few Kelvin [1]. 

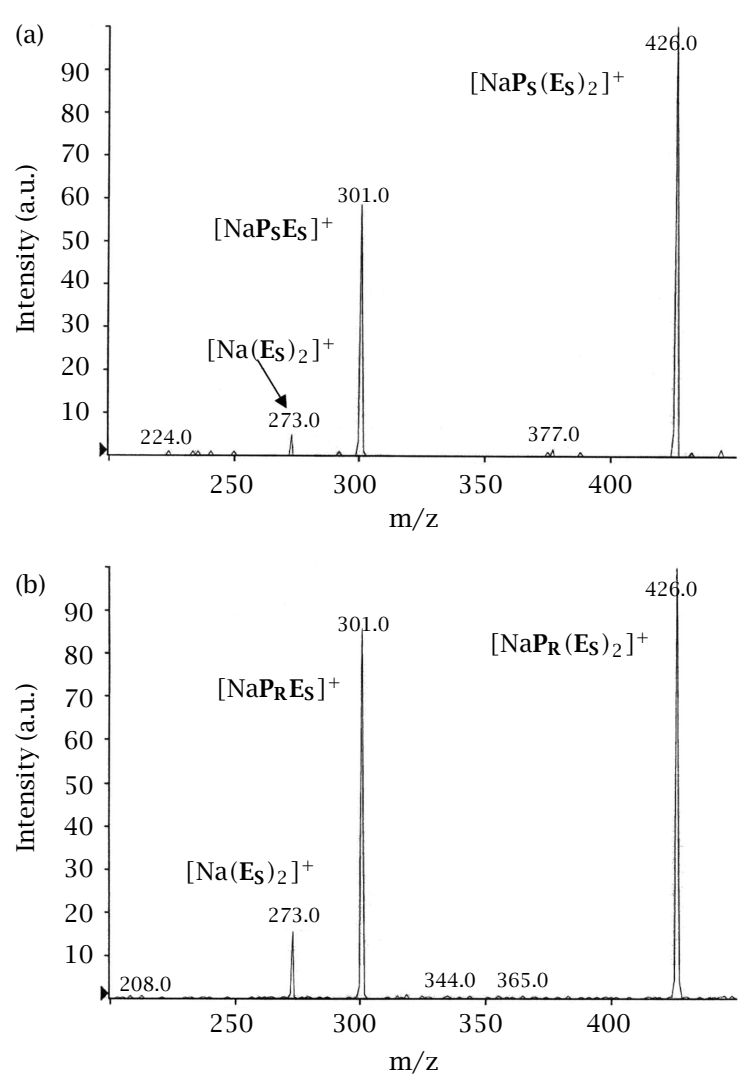

Figure 3. ESI-CID-MS ${ }^{2}$ spectrum of $\left[\mathrm{NaP}_{\mathbf{S}}\left(\mathbf{E S}_{\mathbf{S}}\right)_{2}\right]^{+}$(a) and $\left[\mathrm{NaP}_{\mathbf{R}}\left(\mathbf{E}_{\mathbf{S}}\right)_{2}\right]^{+}$(b). The spectra are the resulting of 300 scans collected at $8 \mathrm{eV}$.

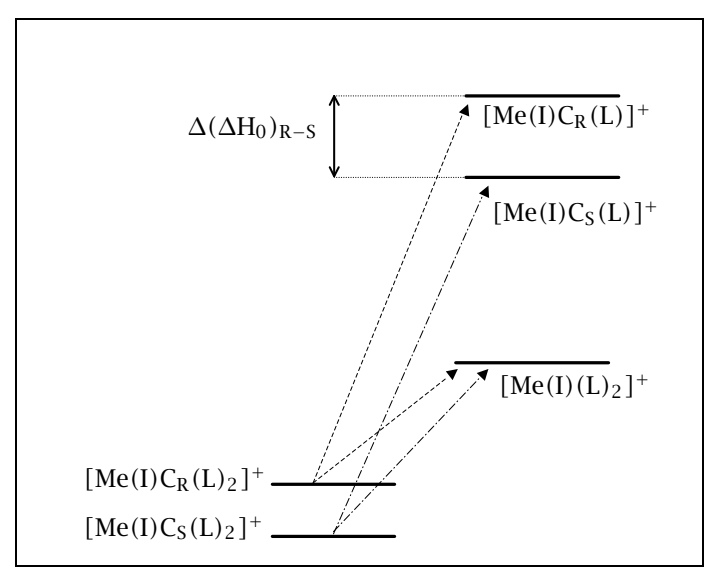

Figure 4. Potential energy levels of the $\left[\mathrm{Me}(\mathrm{I}) \mathrm{C}_{\mathrm{S}} \mathrm{L}_{2}\right]^{+}$and $\left[\mathrm{Me}(\mathrm{I}) \mathrm{C}_{\mathrm{R}} \mathrm{L}_{2}\right]^{+}$fragmentation.

From the table it appears that the ionized heterochiral complexes coordinated by a metal are generally more stable than the homochiral analogues. The ionic radius of the complexing metal doesn't appear to have an influence on the stability of the clusters.
Table 1. Enantiodifferentiation of chiral $\alpha$-aminophosphonic acids by ESI-CID-MS ${ }^{2}$ fragmentation of their diastereomeric $\left[\mathrm{Me}(\mathrm{I}) \mathrm{C}(\mathrm{L})_{2}\right]^{+}$.

\begin{tabular}{ccccc}
\hline $\mathrm{C} / \mathrm{L}$ & $\mathrm{Me}(\mathrm{I})$ & $\mathrm{R}_{\text {chiral }}=\mathrm{R}_{\mathrm{R}} / \mathrm{R}_{\mathrm{S}}$ & $\begin{array}{c}\Delta\left(\Delta H_{0}\right)_{\mathrm{R}-\mathrm{S}} \\
(\mathrm{KJ} \mathrm{mol})^{-1}(\mathrm{a})\end{array}$ & $\begin{array}{c}\text { Cluster Stability } \\
\text { Order }\end{array}$ \\
\hline \multirow{2}{*}{$\mathrm{P}$} & $\mathrm{H}^{+}$ & $1.22 \pm 0.12$ & $+1.6 \pm 0.7$ & hetero $>$ homo \\
& $\mathrm{Li}^{+}$ & $0.80 \pm 0.08$ & $-1.8 \pm 0.7$ & homo $>$ hetero \\
& $\mathrm{Na}^{+}$ & $1.27 \pm 0.13$ & $+1.9 \pm 0.7$ & hetero $>$ homo \\
$\mathrm{E}$ & $\mathrm{K}^{+}$ & $1.10 \pm 0.11$ & $+0.8 \pm 0.7$ & hetero $>$ homo \\
\hline \multirow{2}{*}{$\mathrm{S}$} & $\mathrm{H}^{+}$ & $0.90 \pm 0.09$ & $-1.0 \pm 0.7$ & homo $>$ hetero \\
& $\mathrm{Li}^{+}$ & $1.28 \pm 0.13$ & $+1.9 \pm 0.7$ & hetero $>$ homo \\
& $\mathrm{Na}^{+}$ & $1.30 \pm 0.13$ & $+2.0 \pm 0.7$ & hetero $>$ homo \\
$\mathrm{E}$ & $\mathrm{K}^{+}$ & $1.24 \pm 0.12$ & $+1.7 \pm 0.7$ & hetero $>$ homo \\
\hline \multirow{2}{*}{$\mathrm{H}$} & $\mathrm{H}^{+}$ & $0.86 \pm 0.09$ & $-1.2 \pm 0.7$ & homo $>$ hetero \\
& $\mathrm{Li}^{+}$ & $1.0 \pm 0.1$ & - & hetero $\approx$ homo \\
\multirow{2}{*}{$\mathrm{E}$} & $\mathrm{Na}^{+}$ & $1.1 \pm 0.11$ & $+0.8 \pm 0.7$ & hetero $>$ homo \\
& $\mathrm{K}^{+}$ & $1.50 \pm 0.11$ & $+3.2 \pm 0.7$ & hetero $>$ homo \\
\hline
\end{tabular}

(a) Assuming $T_{\text {eff }}=950 \mathrm{~K}$.

\section{CONCLUSIONS}

In this paper we have reported the study of direct pulsed laser ablation of solid metal-aminophosphonic acid mixtures and shown that gas phase ionized metalaminophosphonic acid complexes can be generated. The relative abundance of the pure $\alpha$-aminophosphonic acid complexes with respect to the metal bonded clusters are generally very low, indicating that the metal can enhance the $\alpha$-aminophosphonic acid coordination and that the complexes formed are stable at the ablation temperature. Being very important the role played in solutions by metal ion-biomolecules complexes in many aspects of everyday life, it is evident how important is such a result to get information on the capability of metals to bond one or more $\alpha$-aminophosphonic acid molecules in gaseous phase.

Furthermore metal-aminophosphonic acid complexes have shown to be a useful mean to help discrimination of $\mathrm{R}$ and $\mathrm{S} \alpha$-aminophosphonic acid. Tetrameric $\left[\mathrm{Me}(\mathrm{I}) \mathrm{C}(\mathrm{L})_{2}\right]^{+}$complexes, when in the CID process undergo fragmentation, give the corresponding trimeric forms by loss of an acidic ligand (either $\mathrm{C}$ or $\mathrm{L}$ ). The relative rates of the two competing fragmentations, i.e. $\left[\mathrm{Me}(\mathrm{I}) \mathrm{C}(\mathrm{L})_{2}\right]^{+} \rightarrow[\mathrm{Me}(\mathrm{I}) \mathrm{CL}]^{+}+\mathrm{L}$; $\left[\mathrm{Me}(\mathrm{I}) \mathrm{C}(\mathrm{L})_{2}\right]^{+} \rightarrow\left[\mathrm{Me}(\mathrm{I})(\mathrm{L})_{2}\right]^{+}+\mathrm{C}$, are measured from the corresponding $[\mathrm{Me}(\mathrm{I}) \mathrm{CL}]^{+} /\left[\mathrm{Me}(\mathrm{I})(\mathrm{L})_{2}\right]^{+}$ ion abundance ratios. If optically active $\alpha$ aminophosphonic acids $\left(\mathrm{C}_{\mathrm{R}}\right.$ and $\left.\mathrm{C}_{\mathrm{S}}\right)$ are employed, the comparison of the $\left[\mathrm{Me}(\mathrm{I}) \mathrm{C}_{\mathrm{R}} \mathrm{L}\right]^{+} /\left[\mathrm{Me}(\mathrm{I})(\mathrm{L})_{2}\right]^{+}$and $\left[\mathrm{Me}(\mathrm{I}) \mathrm{C}_{S} \mathrm{~L}\right]^{+} /\left[\mathrm{Me}(\mathrm{I})(\mathrm{L})_{2}\right]^{+}$ratios provides a measure of the relative stability of the homochiral $\left[\mathrm{Me}(\mathrm{I}) \mathrm{C}_{S} \mathrm{~L}\right]^{+}$ vs the heterochiral $\left[\mathrm{Me}(\mathrm{I}) \mathrm{C}_{\mathrm{R}} \mathrm{L}\right]^{+}$adducts and, therefore, a means for enantiodiscriminating the chiral $C_{R}$ and $C_{S}$ solutes. The ionized heterochiral complexes coordinated by a metal are generally more stable than the homochiral analogues. The ionic radius of the 
complexing metal doesn't appear to have an influence on the stability of the clusters.

From the reported results it can be inferred that the ESI-CID-MS ${ }^{2}$ technique proves suitable for detecting the abundance of chiral molecules of large biochemical interest, such as the $\alpha$-aminophosphonic acids, in complex matrices. In the frame of the kinetic method, the measured fragmentation intensities are correlated to the termochemical properties of the $\alpha$ aminophosphonic acids.

\section{ACKNOWLEDGEMENTS}

This work was supported by the Ministero dell'Università e della Ricerca Scientifica e Tecnologica (MURST) and the Consiglio Nazionale delle Ricerche (CNR): Progetto Finalizzato MSTA II.

\section{References}

[1] S. Piccirillo, C. Bosman, D. Toja, A. Giardini Guidoni, M. Pierini, A. Troiani, and M. Speranza, Angew. Chem. Int. Ed. Engl. 36 (1997), 1729.

[2] A. R. Al-Rabaa, E. Bréhéret, F. Lahmani, and A. Zehnacker, Chem. Phys. Lett. 237 (1995), 480.

[3] K. Vékey and G. Czira, Anal. Chem. 69 (1997), 1700.

[4] F. Piuzzi, I. Dimicoli, M. Mons, B. tardivel, and Q. Zhao, Chem. Phys. Lett. 320 (2000), 282; E. Nir, L. Grace, B. Brauer, and M. S. de Vries, J. Am. Chem. Soc. 121 (1999), 4896.

[5] W. A. Tao, D. Zhang, F. Wang, P. Thomas, and R. G. Cooks, Anal. Chem. 71 (1999), 4427.

[6] C. E. Mc Kenna, L. A. Khawli, A. Bapat, V. Harutunian, and Y-C. Cheng, Biochemical Pharmacology 36 (1987), 3103.

[7] Cristina Calcagni, Thesis in Chemistry, A. A. 19992000. 


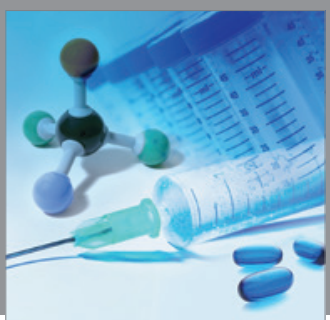

International Journal of

Medicinal Chemistry

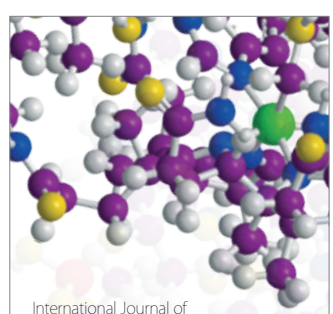

Carbohydrate Chemistry

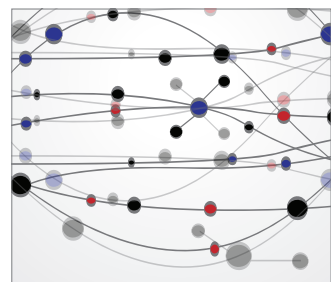

The Scientific World Journal
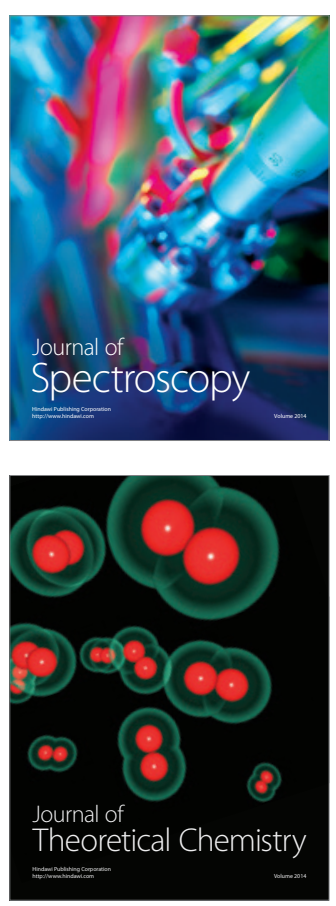
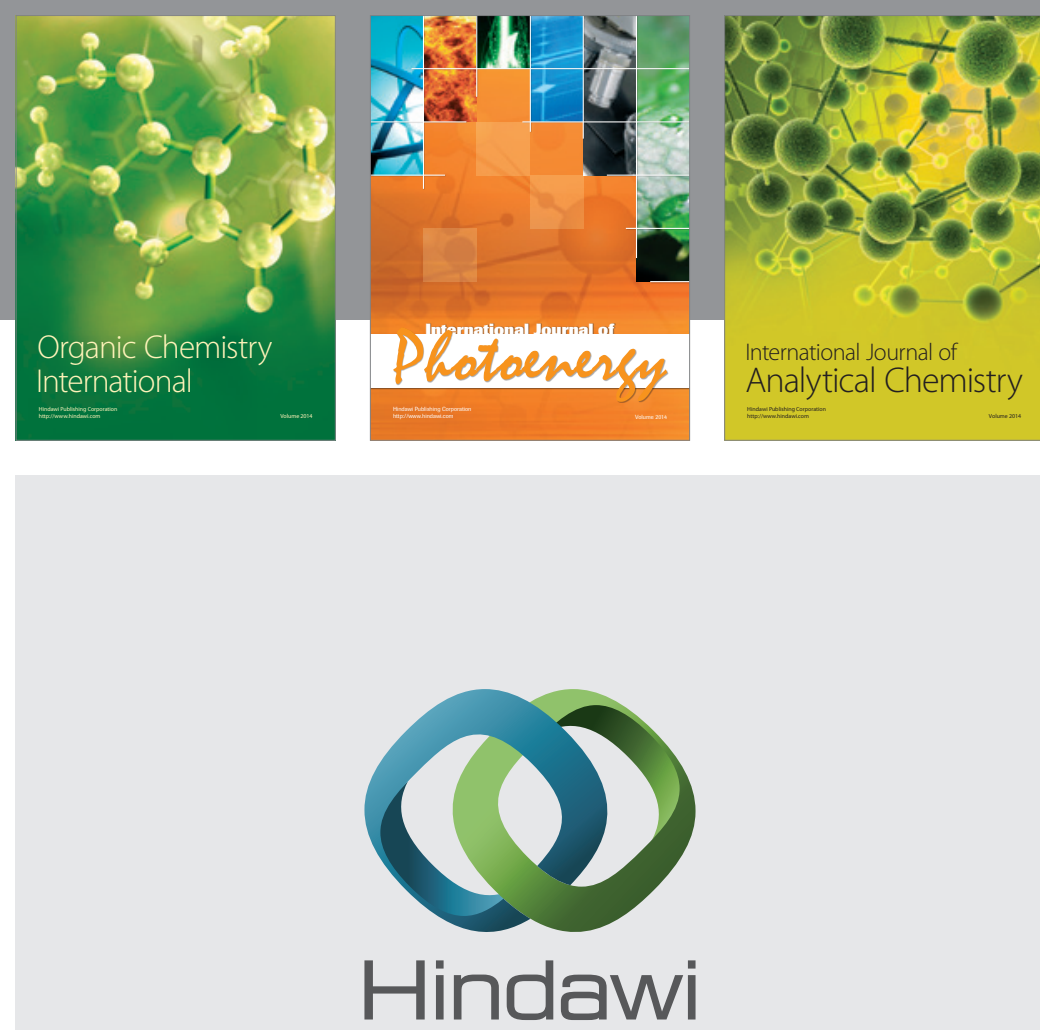

Submit your manuscripts at

http://www.hindawi.com
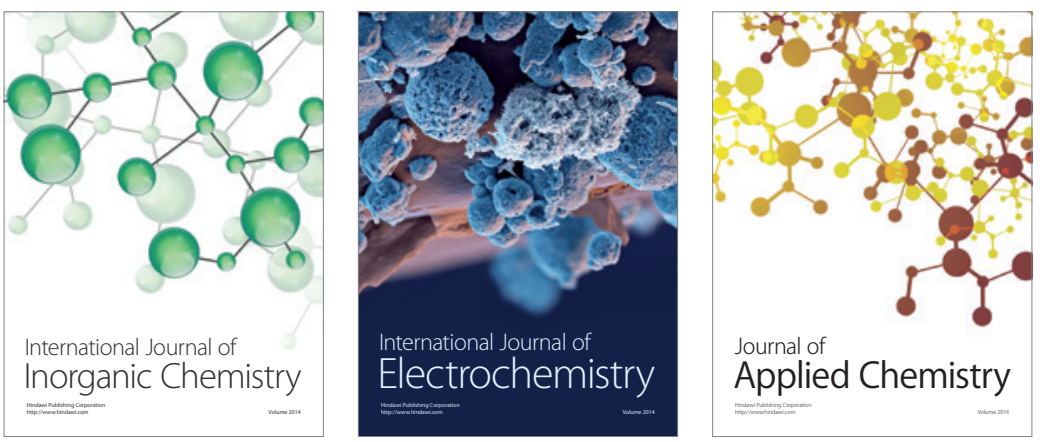

Journal of

Applied Chemistry
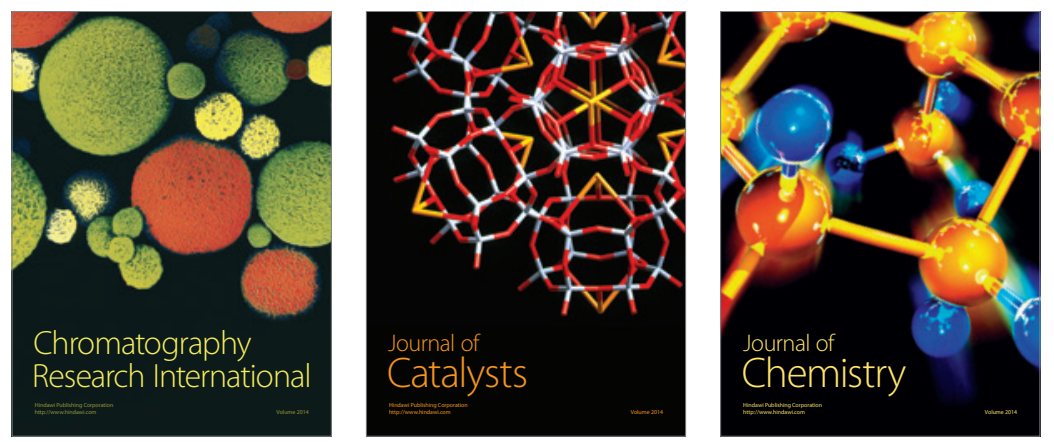
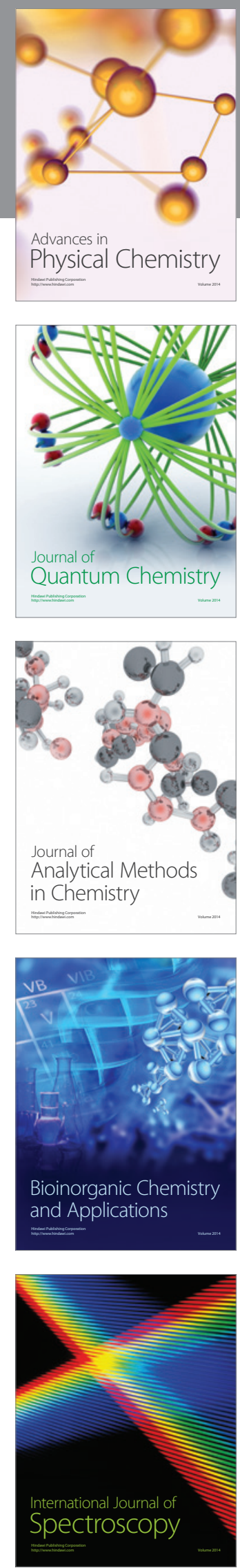